\title{
$\gamma$-Tocotrienol suppresses growth and sensitises human colorectal tumours to capecitabine in a nude mouse xenograft model by down-regulating multiple molecules
}

\author{
Sahdeo Prasad ${ }^{\star}, 1,2$, Subash C Gupta ${ }^{1,2,3}$, Amit K Tyagi ${ }^{1}$ and Bharat B Aggarwal ${ }^{1,4}$ \\ ${ }^{1}$ Department of Experimental Therapeutics, The University of Texas MD Anderson Cancer Center, 1515 Holcombe Boulevard, \\ Houston, TX 77030, USA
}

Background: Colorectal cancer (CRC) is one of the most common malignancies worldwide and even develops resistance to chemotherapeutic agents over time. As a result survival for patients with CRC remains poor.

Method: We investigated both in vitro and in vivo effects of $\gamma$-tocotrienol $(\gamma$-T3) alone and in combination with capecitabine. Apoptosis and cytotoxicity assays were performed by MTT and FACS analysis, whereas expression of proteins was investigated using western blotting and immunohistochemistry.

Results: The $\gamma$-T3 inhibited the proliferation of CRC cells with wild-type or mutated KRAS. It also induced apoptosis, inhibited colony formation, and suppressed key regulators of cell survival, cell proliferation, invasion, angiogenesis, and metastasis. Furthermore, $\gamma$-T3 enhanced the anticancer effects of capecitabine in CRC cells. In a nude mouse xenograft model of human CRC, oral administration of $\gamma$-T3 inhibited tumour growth and enhanced the antitumour efficacy of capecitabine. Western blot and immunohistochemical analysis results indicated that expression of Ki-67, cyclin D1, MMP-9, CXCR4, NF- $\kappa$ B/p65, and VEGF was lower in tumour tissue from the combination treatment group. Combination treatment also downregulated NF- $\kappa \mathrm{B}$ and NF- $\kappa \mathrm{B}-$ regulated gene products.

Conclusions: Our findings suggest that $\gamma$-T3 inhibited the growth of human CRC and sensitised CRC to capecitabine by regulating proteins linked to tumourigenesis.

Colorectal cancer (CRC) is one of the most common malignancies and is the third leading cause of cancer-related deaths in the United States. The American Cancer Society estimates that 134490 new cases of CRC will be diagnosed and 49190 individuals will die of this disease in the United States in 2016. Globally, the incidence of CRC varies over 10-fold (Siegel et al, 2015). The highest incidence rates are in developed countries such as the United States, and the lowest rates are found in developing countries. These differences in incidence rates appear to be attributable to geographical differences in diet and environmental exposure (Torre et al, 2015). Although environmental and genetic factors are the major risk factors for CRC, lifestyle also contributes to the development of this disease.

Extensive research within the past few years has indicated that $\mathrm{CRC}$ is caused by dysregulation of numerous signalling pathways

*Correspondence: Dr S Prasad; E-mail: sprasad@mdanderson.org; spbiotech@gmail.com

${ }^{2}$ These authors contributed equally to this work.

${ }^{3}$ Current address: Department of Biochemistry, Institute of Science, Banaras Hindu University, Varanasi, Uttar Pradesh 221005, India.

${ }^{4}$ Current address: Inflammation Research Institute, San Diego, CA, USA.

Received 6 July 2016; revised 14 July 2016; accepted 26 July 2016; published online 30 August 2016

(c) 2016 Cancer Research UK. All rights reserved 0007 - 0920/16 
and gene products, including growth factors, growth factor receptors, protein kinases, inflammatory cytokines, inflammatory enzymes, proapoptotic proteins, antiapoptotic proteins, tumour suppressors, and transcription factors (Aggarwal et al, 2013). Furthermore, most CRCs express constitutively active transcription factor nuclear factor $-\kappa \mathrm{B} / \mathrm{p} 65(\mathrm{NF}-\kappa \mathrm{B} / \mathrm{p} 65)$. Activated NF- $\kappa \mathrm{B}$ regulates the expression of various proteins linked to survival (e.g., antiapoptotic proteins $\mathrm{Bcl}-2$, Bcl-xL, cFLIP, IAP-1, IAP-2, and survivin), proliferation (e.g., c-Myc and cyclin D1), inflammation (COX-2, cytokines), invasion (e.g., MMP-9, ICAM-1, ELAM-1, and VCAM-1), and neoangiogenesis (e.g., VEGF) (Aggarwal et al, 2013). In addition, Liu et al (2013) showed that survivin along with CD44v3 is critical for CRC cell apoptosis, proliferation, and invasiveness.

Although screening modalities for early detection and therapeutic management of CRC have improved considerably (Lee and Sonnenberg, 2013), this disease still needs better treatment modalities. As long-term use of cytotoxic chemotherapy and radiotherapy can have severe side effects and as tumours can develop resistance to these therapies, agents that can overcome tumour resistance and can control multiple signalling pathways are needed to treat CRC. $\gamma$-Tocotrienol $(\gamma$-T3; Figure 1A), an unsaturated tocopherol belonging to the vitamin $\mathrm{E}$ family of compounds, may be one such agent. Palm oil, rice bran, barley, and wheat germ are rich sources of $\gamma$-T3.

Accumulating evidence suggests that $\gamma$-T3 mediates activity against various chronic diseases, including cardiovascular diseases, neurologic diseases, diabetes, and cancer (Qureshi et al, 1991; Sen et al, 2004; Schaffer et al, 2005; Chin et al, 2008; Kuhad et al, 2009). The $\gamma$-T3 has shown anticancer activity against cancers of the colon, pancreas, breast, liver, lungs, kidney, prostate, and skin; multiple myeloma; and other cancers both in vitro (Takahashi and Loo, 2004; Ahn et al, 2007; Aggarwal et al, 2010; Kannappan et al, 2010; Campbell et al, 2011; Kannappan et al, 2012) and in vivo (Gould et al, 1991; Wada et al, 2005; Nakagawa et al, 2007; Yamada et al, 2008; Hiura et al, 2009; Kunnumakkara et al, 2010; Manu et al, 2012). Previously, we have shown that the anticancer potential of $\gamma$-T3 is mediated though the induction of apoptosis and suppression of cell growth and proliferation in various types of cancer cells (Kannappan et al, 2012). In addition, $\gamma$-T3 has been shown to downregulate TGF $\beta 2$, SMAD-2, and p38 (Campbell et al, 2011), NF- $\kappa \mathrm{B}$ (Ahn et al, 2007), the phosphatidylinositol 3-kinase/ 3-phosphoinositide-dependent kinase 1/AKT pathway (Shah and Sylvester, 2005; Samant and Sylvester, 2006), and c-Myc expression (Sun et al, 2008). Studies have also shown that $\gamma$-T3 activates death receptors (Kannappan et al, 2010), Nrf2 (Hsieh et al, 2010), caspase-3, caspase-8, and caspase-9 (Ahn et al, 2007; Kannappan et al, 2010).

Whether $\gamma$-T3 can sensitise CRC to capecitabine in vitro and in a xenograft mouse model was not known. In the current study, we investigated whether $\gamma$-T3 alone or in combination with capecitabine, a standard treatment for CRC, inhibits the growth and metastasis of human CRC in vitro and in a xenograft mouse model. Our results indicate that $\gamma$-T3 inhibited proliferation of different CRC cells by suppressing proteins that regulate cell growth. Furthermore, $\gamma$-T3 significantly inhibited the growth of CRC tissue and enhanced the antitumour effects of capecitabine by downregulating several cell signalling molecules.

\section{MATERIALS AND METHODS}

Materials. A solution of palm oil-derived $\gamma$-T3 $\left(50 \mathrm{mmoll}^{-1}\right.$; Davos Life Science, Singapore) was prepared in dimethyl sulphoxide for in vitro experiments, was stored in small aliquots at $-20^{\circ} \mathrm{C}$, and then was diluted in cell culture medium as needed.
Antibodies against p65, ICAM-1, cyclin D1, MMP-9, survivin, cIAP-1, cIAP-2, c-Myc, Bcl-2, and Bcl-xL were obtained from Santa Cruz Biotechnology (Dallas, TX, USA). Antibody against VEGF was obtained from Lab Vision/NeoMarkers (Fremont, CA, USA), and antibody against CXCR4 was purchased from Abcam (Cambridge, MA, USA). The liquid 3,3'-diaminobenzidine (DAB chromogen)-horseradish peroxidase used for immunohistochemical analysis was obtained from DakoCytomation (Glostrup, Denmark). Penicillin, streptomycin, Dulbecco's modified Eagle's medium (DMEM), RPMI-1640 medium, DMEM/F12, and fetal bovine serum (FBS) were obtained from Life Technologies (Carlsbad, CA, USA). All other chemicals were obtained from Sigma-Aldrich (St Louis, MO, USA), unless otherwise stated.

Cell lines. Human CRC cell lines HCT 116, HT-29, and Caco-2 were obtained from the American Type Culture Collection (Manassas, VA, USA). The HCT 116 cells were cultured in DMEM, and the HT-29 and Caco-2 cells were cultured in RPMI1640 medium. To facilitate the monitoring of tumour growth in the mice, HCT 116 was stably transfected with the luciferase reporter gene. Luciferase-transfected HCT 116 cells were cultured in DMEM/F12. Each medium was supplemented with FBS (10\%), penicillin $\left(100 \mathrm{U} \mathrm{ml}^{-1}\right)$, and streptomycin $\left(100 \mu \mathrm{g} \mathrm{ml}^{-1}\right)$.

MTT assay. The viability and proliferation of cells treated with $\gamma$-T3 were determined by MTT assay (Kunnumakkara et al, 2010). Briefly, cells (2000 per well) were incubated for desired time period with $\gamma$-T3 in quadruplicate in a 96-well plate at $37^{\circ} \mathrm{C}$. After $2 \mathrm{~h}$ of addition of MTT solution, lysis buffer (20\% sodium dodecyl sulphate (SDS) and 50\% dimethylformamide) was added. Cells were incubated overnight at $37^{\circ} \mathrm{C}$, and then absorbance was measured at $570 \mathrm{~nm}$.

Propidium iodide staining for apoptosis. Propidium iodide (PI) staining for cell distribution across the cell cycle was performed with a BD FACSCalibur flow cytometer (BD Biosciences, San Jose, CA, USA), as described previously (Kannappan et al, 2010). A total of 20000 events were analysed by flow cytometry using an excitation wavelength set at $488 \mathrm{~nm}$ and emission set at $610 \mathrm{~nm}$.

Annexin V/PI assay. The Annexin V/PI assay is used to detect the translocation of phosphatidylserine to the cell surface, an early indicator of apoptosis. Briefly, treated cells $\left(2 \times 10^{6}\right)$ were washed in phosphate-buffered saline (PBS) solution, were suspended in binding buffer $(100 \mu \mathrm{l})$ containing a FITC antiAnnexin V antibody and PI, and then were analysed with a flow cytometer (BD FACSCalibur).

Live/dead cell assay. The live/dead cell assay (Molecular Probes, Eugene, OR, USA) was performed to determine the apoptotic potential of $\gamma$-T3 and capecitabine in CRC cells. Briefly, cells (5000 per well) were incubated in chamber slides with $\gamma$-T3 and/or capecitabine for $24 \mathrm{~h}$. Cells were then stained with assay reagents for $30 \mathrm{~min}$ at room temperature. Cell viability was determined by counting live (green) and dead (red) cells under a fluorescent microscope.

Clonogenic assay. HCT 116 cells (500 per well) were treated with $\gamma$-T3 and/or capecitabine for $12 \mathrm{~h}$. The medium was replaced with fresh medium, and the cells were allowed to form colonies for 9 days. Colonies were stained with $0.3 \%$ crystal violet solution for $20 \mathrm{~min}$. Wells were washed with distilled water to visualise the cell colonies.

Western blot analysis. Whole-cell protein $(30-50 \mu \mathrm{g})$ from cell lines and tumour tissue was loaded on $7.5 \%$ or $10 \%$ SDS-polyacrylamide gel electrophoresis gel, transferred to a nitrocellulose membrane, blocked with 5\% non-fat milk, and probed with respective antibodies. The membranes were washed and exposed to horseradish peroxidase-conjugated secondary 
A<smiles>CC(C)=CCC/C(C)=C/CC/C(C)=C/CCC1(C)CCc2cc(O)c(C)c(C)c2O1</smiles>

B
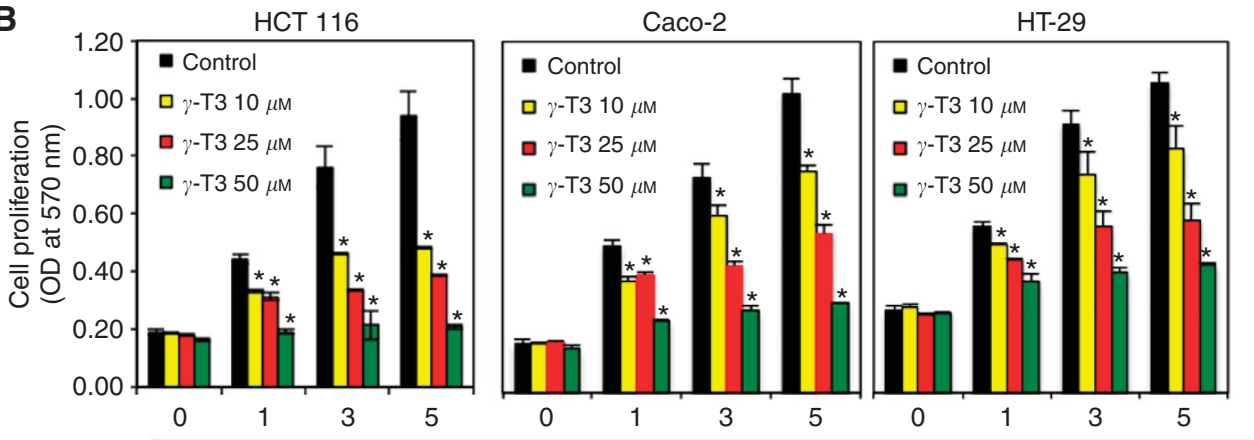

C
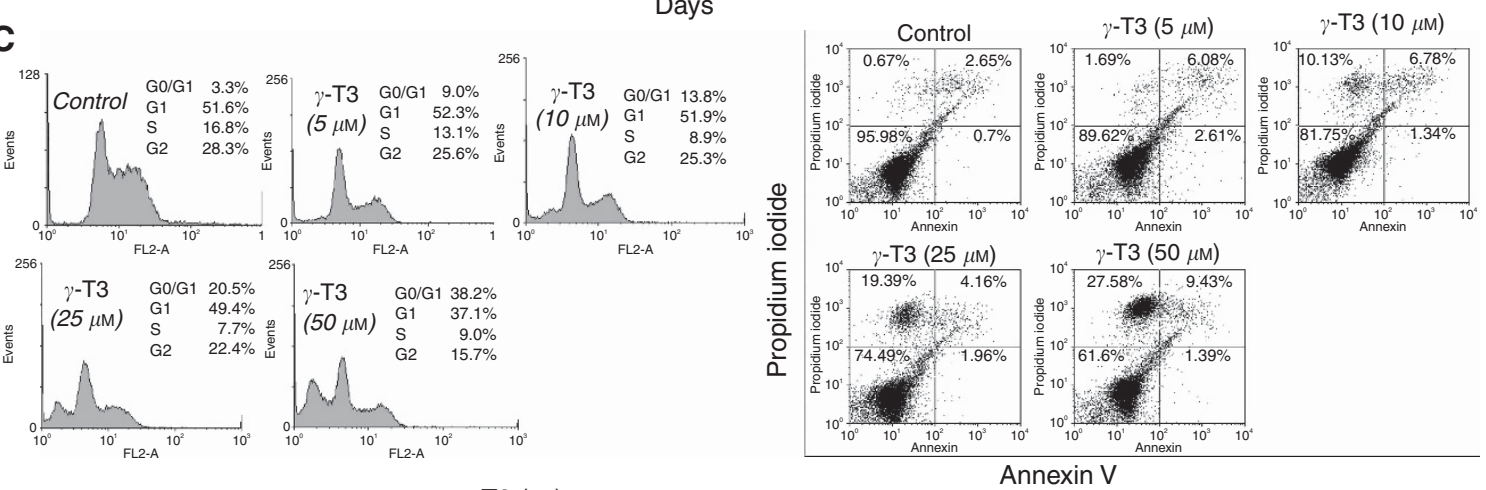

D

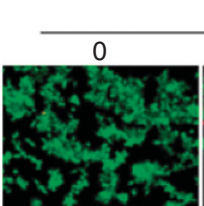

$1 \pm 0.5 \%$

$\gamma$-T3 $(\mu \mathrm{M})$

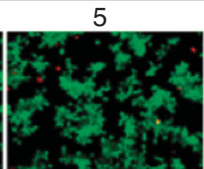

$6.1 \pm 1.7 \%$

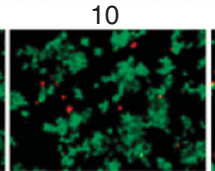

$10.4 \pm 0.7 \%$

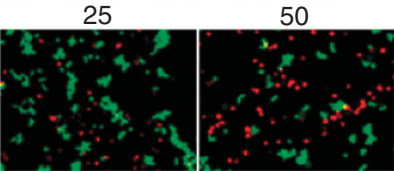

$33.3 \pm 2.6 \%$

$49.4 \pm 1.2 \%$

E
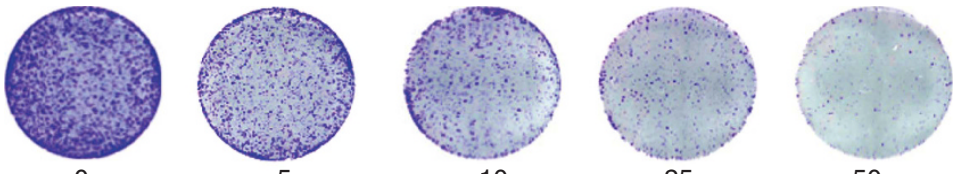

50

$\gamma$-T3 $(\mu \mathrm{m})$

25
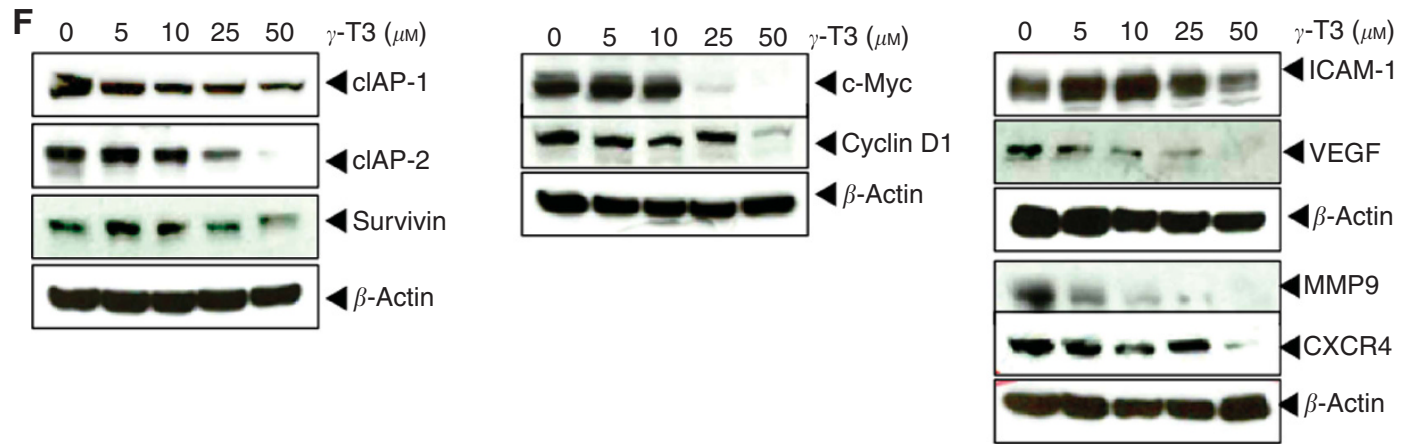

Figure 1. $\gamma$-Tocotrienol ( $\gamma$-T3) inhibits proliferation and induces apoptosis in CRC. (A) Chemical structure of $\gamma$-T3. (B) The HCT 116, HT-29, and Caco- 2 cells were treated with the indicated concentrations of $\gamma$-T3 for 1,3 , and 5 days. Cell viability was then analysed by the MTT method. *Significant $(P<0.01)$ over controls. OD, optical density. (C) HCT 116 cells were treated with the indicated concentrations of $\gamma$-T3 for 24 h. Cells were then stained with PI alone (left) or Annexin V and PI (right) and then were analysed by using fluorescence-activated cell sorting. (D) Cells were treated with the indicated concentrations of $\gamma$-T3. After $24 \mathrm{~h}$, cell death was determined by live/dead cell assay. (E) HCT 116 (500 cells per well) were treated with different concentrations of $\gamma$-T3 for $12 \mathrm{~h}$. The medium was replaced with fresh medium. After 9 days, the cells were stained with crystal violet and were counted for colony formation (right panel). *Significant $(P<0.05)$ over controls as shown in bar diagram. $(\mathbf{F})$ Cells were pretreated with $\gamma$-T3 at the indicated concentrations for $24 \mathrm{~h}$. Whole-cell extracts were prepared and analysed by western blotting with the indicated antibodies. $\beta$-Actin was used as an internal control. 
antibodies, and the proteins were detected by electrochemiluminescent reagent (Amersham/GE Healthcare Life Sciences, Pittsburgh, PA, USA).

Electrophoretic mobility shift assay. To study the effects of compounds on NF- $\kappa \mathrm{B}$ activation, we prepared nuclear extract from cells and performed an electrophoretic mobility shift assay, as described previously (Chaturvedi et al, 2000).

Animals. The 4-week-old male athymic nu/nu mice were obtained from the breeding colony of the Department of Experimental Radiation Oncology at UT MD Anderson Cancer Center. The animals were housed and maintained with food, light, and water in standard manner as described previously (Kunnumakkara et al, 2009). Our experimental protocol was reviewed and approved by the institutional animal care and use committee at The University of Texas MD Anderson Cancer Center (Houston, TX, USA).

Nude mouse xenograft model. The HCT 116 cells stably transfected with luciferase were harvested from subconfluent cultures after brief exposure to $0.25 \%$ trypsin and $0.2 \%$ EDTA. Single-cell suspensions with $>90 \%$ viability were used for the injections. Luciferase-transfected HCT 116 cells $\left(2 \times 10^{6}\right)$ in PBS $(50 \mu \mathrm{l})$ were injected subcutaneously into the leg of each mouse with a 27 -gauge needle.

At 10 days after tumour implantation, on the basis of the initial IVIS image that detect growth and size of tumour, the mice were randomised into four groups (5 mice/group): (1) corn oil vehicle (100 $\mu$ l, daily); (2) $\gamma$-T3 alone (100 $\mathrm{mg} \mathrm{kg}^{-1}, 5$ times per week); (3) capecitabine alone (60 $\mathrm{mg} \mathrm{kg}^{-1}$, twice per week); and (4) $\gamma$-T3 (100 $\mathrm{mg} \mathrm{kg}^{-1}, 5$ times per week) and capecitabine $\left(60 \mathrm{mg} \mathrm{kg}^{-1}\right.$, twice per week). All treatments were administered orally for 2 weeks.

Tumours were measured every other day by Vernier calipers, and the following formula was used to calculate tumour volume: $0.5 \times L \times W^{2}$, where $L$ represents tumour length and $W$ represents tumour width (Kunnumakkara et al, 2010). Tumour volumes were also measured weekly using the noninvasive IVIS 200 bioluminescence imaging system and Living Image In Vivo Imaging Software (Caliper Life Sciences, Hopkinton, MA, USA). Briefly, animals were injected intraperitoneally with D-luciferin potassium salt at a dose of $150 \mathrm{mg} \mathrm{kg}^{-1}$ of body weight and then were anaesthetised with a $2.5 \%$ isoflurane/air mixture. After $10 \mathrm{~min}$ in an acrylic chamber, mice were kept in a vertical position, and the total photons emerging from the active luciferase within the animals were detected. The signal intensity was quantified as the sum of all detected photons within the region of interest per second per steradian (photons $\mathrm{s}^{-1} \mathrm{~cm}^{-2} \mathrm{sr}^{-1}$ ).

At 4 days after the last treatment, the mice were killed, and each tumour was excised and divided into three parts. The first part of the tumour tissue was formalin fixed, the second part was fixed in optimal cutting temperature compound for immunohistochemical analysis, and the third part was snap frozen in liquid nitrogen and stored at $-80^{\circ} \mathrm{C}$ for western blotting analysis.

Ki-67 immunohistochemical analysis. Frozen sections $(5 \mu \mathrm{m})$ were stained with anti-Ki-67 (rabbit monoclonal clone SP6, Lab Vision/NeoMarkers) antibody, as previously described (Kunnumakkara et al, 2010).

Immunolocalisation of NF- $\kappa \mathrm{B} / \mathrm{p} 65$, cyclin D1, CXCR4, VEGF, and MMP-9 in tumour samples. The nuclear localisation of $\mathrm{NF}-\kappa \mathrm{B} / \mathrm{p} 65$ and the expression of cyclin D1, MMP-9, CXCR4, and VEGF were examined using an immunohistochemical method described previously (Kunnumakkara et al, 2010). Pictures were captured with a Photometrics Scientific CoolSNAP CF colour camera (Photometrics, Tucson, AZ, USA) and were analysed with MetaMorph software, version 4.6.5 (Molecular Devices, Sunnyvale, CA, USA).
Statistical analysis. Data are presented as mean \pm s.d. Student's $t$-test was used to compare means of two independent variables. One-way analysis of variance was used to determine the statistical differences between more than two groups. Statistical significance was established as $P<0.05$. A significant interaction was interpreted by a subsequent median effect principle of the Chou-Talalay method.

\section{RESULTS}

Our goal in the current study was to determine whether $\gamma$-T3 can improve the treatment effect of capecitabine in advanced CRC. Thus, to determine this effect a human CRC implanted nude mouse model was used. The $\gamma$-T3 can affect the growth of CRC and enhance the effect of capecitabine, which is used routinely to treat CRC. We used three different well-characterised human colon cancer cell lines (HCT 116, HT-29, and Caco-2) that exhibit distinct characteristics.

$\gamma$-T3 inhibits the proliferation of CRC cells in vitro. We first investigated whether $\gamma$-T3 inhibited the proliferation of human CRC cells. We used one cell line with mutated KRAS (HCT 116) and two cell lines with wild-type KRAS (HT-29 and Caco-2). We found that $\gamma$-T3 significantly inhibited cell proliferation in all three cell lines in a dose- and time-dependent manner $(P<0.01)$. The HCT 116 cells were more sensitive to $\gamma$-T3 than HT-29 and Caco-2 cells (Figure 1B).

$\gamma$-T3 induces apoptosis of CRC cells in vitro. Next, we investigated whether $\gamma$-T3 induced apoptosis in CRC cells by PI staining method. The HCT 116 cells were treated with different concentrations of $\gamma$-T3 for $24 \mathrm{~h}$, and then the sub-G1 fraction, an indicator of apoptosis, was analysed. The results indicated that $\gamma$-T3 induced apoptosis in a dose-dependent manner (Figure 1C, left panel). Our results showed that the number of Annexin $\mathrm{V}$-positive cells significantly increased as the $\gamma$-T3 dose increased (Figure 1C, right panel).

To confirm the MTT assay and fluorescence-activated cell sorting analysis results, we treated the HCT 116 cells with various concentrations of $\gamma$-T3 for $24 \mathrm{~h}$ and then performed a live/dead cell assay. As indicated in Figure 1D, $\gamma$-T3 induced cell death in a dosedependent manner. These results confirmed that $\gamma$-T3 inhibited cell growth and induced apoptosis.

We also investigated whether $\gamma$-T3 suppressed the ability of HCT 116 cells to form colonies. At the highest concentration of $\gamma$-T3, the total number of colonies was significantly lower than the number of colonies in the control group (Figure 1E).

$\gamma$-T3 suppresses the expression of tumourigenic proteins. We investigated whether $\gamma$-T3 alone suppressed the expression of proteins linked to cell survival and found that $\gamma$-T3 inhibited cIAP-1, cIAP-2, and survivin (Figure 1F, left panel). We next investigated whether $\gamma$-T3 alone inhibited the expression of proliferationrelated proteins. Our results showed that $\gamma$-T3 inhibited the expression of cyclin D1 and c-Myc in HCT 116 cells, both of which are known to contribute to cell proliferation (Figure 1F, middle panel). The $\gamma$-T3 also inhibited the expression of proteins involved in tumour cell invasion, metastasis, and angiogenesis (MMP-9, VEGF, ICAM-1, and CXCR4) (Figure 1F, right panel).

$\gamma$-T3 enhances capecitabine-induced cell death. We next investigated whether $\gamma$-T3 downregulation of tumour cell survival proteins enhanced the apoptotic effects of capecitabine in HCT 116 cells. Using Annexin V/PI staining and flow cytometry, we found that samples treated with both $\gamma$-T3 and capecitabine had more apoptotic cells than the other samples (Figure 2A, left panel). The apoptotic effect of $\gamma$-T3 was also examined by live/dead cell assay. The cell death induced by either $\gamma$-T3 alone or capecitabine alone was moderate; combination treatment prominently increased 
cell death (Figure 2A, right panel). Cell death (\%) is represented below the image.

We studied combination effect of $\gamma$-T3 and capecitabine in induction of cell death using HCT 116 cells. We found that $\gamma$-T3 and capecitabine are moderately cytotoxic but combination has prominent cytotoxicity (Figure $2 \mathrm{~B}$ ). To evaluate synergistic effects of these two drugs, we calculated the combination index (CI) values using CalcuSyn software based on the median effect principle (Chou, 2006). The obtained CI values demonstrated the positive interactions between $\gamma$-T3 and capecitabine, and synergy was observed for all doses of $\gamma$-T3 and capecitabine combinations in HCT 116 cells. The combination ratio of $\gamma$-T3 and capecitabine $(1: 5)$ resulted in a potent synergistic profile (CI values between $0.43,0.65$, and 0.97$)$ at calculated $\mathrm{ED}_{50}, \mathrm{ED}_{75}$, and $\mathrm{ED}_{90}$, but at $\mathrm{ED}_{95}$ the CI value was 1.23. Thus, we demonstrated that $\gamma-\mathrm{T} 3$ is highly efficient in combination with capecitabine as an anticancer agent against CRC cells in our in vitro models.

$\gamma$-T3 inhibits colony formation of CRC cells. We also performed a long-term colony formation assay, which more closely mirrors the in vivo environment, to determine whether $\gamma$-T3 enhanced the antitumour effects of capecitabine. Figure 2C (upper and lower panels) shows that $\gamma$-T3 alone or capecitabine alone moderately affected the colony-forming ability of HCT 116 cells, but cells treated with both $\gamma$-T3 and capecitabine had substantially fewer colonies than the control cells.

$\gamma$-T3 inhibits constitutive NF- $\kappa$ B activation in CRC cells. We next examined $\gamma$-T3 ability to inhibit constitutive NF- $\kappa$ B activation in HCT 116 cells because NF- $\kappa \mathrm{B}$ has been linked with proliferation. Our results showed that $\gamma$-T3 alone inhibited constitutive NF- $\kappa \mathrm{B}$ activation in HCT 116 cells; however, capecitabine had no effect (Figure 2D).

$\gamma$-T3 enhances capecitabine-induced downregulation of survival, proliferation, and metastasis proteins in CRC cells. We also investigated whether $\gamma$-T3 alone or in combination with capecitabine downregulated the expression of proteins associated with survival, proliferation, invasion, and metastasis. Our results showed that $\gamma$-T3 alone inhibited slightly or moderately the expression of proteins related to survival (survivin, cIAP-1, and cIAP-2), proliferation (cyclin D1 and $\mathrm{c}-\mathrm{Myc}$ ), and metastasis (MMP-9, VEGF, ICAM-1, and CXCR4) in HCT 116 cells (Figure 2E). Cells treated with both $\gamma$-T3 and capecitabine had lower levels of these proteins than the cells treated with single agents.

$\gamma$-T3 inhibits the growth of human CRC in a xenograft nude mouse model. Next we determined whether $\gamma$-T3 inhibited tumour growth in vivo. The experimental protocol is depicted in Figure 3A. As determined by noninvasive bioluminescence imaging measured on first day of treatment and day 16 (Figure 3B), tumour volume increased rapidly in the vehicletreated group. Both $\gamma$-T3 alone and capecitabine alone markedly suppressed tumour growth in the mice. The effect of capecitabine alone and $\gamma$-T3 alone was comparable.

Moreover, after week 2, imaging results showed that mice treated with the combination of $\gamma$-T3 and capecitabine had tumours that were approximately one-third the size of the tumours in the control group (Figure 4A). Results of tumour volume measurement by Vernier calipers also showed that mice treated with either $\gamma$-T3 alone or capecitabine alone had smaller tumours than the vehicle-treated group, and consistent with the IVIS imaging results, $\gamma$-T3 enhanced the effect of capecitabine in the suppression of tumour growth in the mice (Figure 4B). Furthermore, the body weight of treated or untreated mice did not change (Figure 4C).
$\gamma$-T3 inhibits Ki-67 expression in CRC tissue. Because the Ki-67 index indicates cell proliferation, we investigated whether $\gamma$-T3 and capecitabine modulated this biomarker. Immunohistochemical analysis results indicated that the tumour tissue expressed Ki-67. The tumour tissue from mice treated with $\gamma$-T3 alone or capecitabine alone had moderately lower levels of Ki-67 than the tumour tissue from the control mice. Levels of Ki-67 were even lower in the tumour tissues of mice treated with both $\gamma$-T3 and capecitabine (Figure 5A).

$\gamma$-T3 inhibits the expression of cell survival proteins in CRC tissue. We investigated the impact of $\gamma-\mathrm{T} 3$ and capecitabine on the expression of proteins involved in CRC growth. Western blot analysis results indicated that the effects of $\gamma$-T3 alone and capecitabine alone on expression of cell survival proteins were minimal to moderate. However, the tumour tissue from mice treated with both $\gamma$-T3 and capecitabine had significantly lower levels of cell survival proteins cIAP-1, cIAP-2, Bcl-2, Bcl-xL, and survivin than did the tumour tissue from mice in other treatment groups (Figure 5B).

$\gamma$-T3 suppresses the expression of cell proliferation proteins in CRC tissue. Next, we investigated whether $\gamma$-T3 inhibited the expression of cell proliferation protein cyclin D1 in CRC tissue. We found that the tumour tissue from mice treated with $\gamma$-T3 alone or capecitabine alone had moderately lower levels of cyclin D1 than the tumour tissue from mice in the control group. The tumour tissue from mice treated with both $\gamma$-T3 and capecitabine had markedly lower cyclin D1 levels (Figure 5C) and lower levels of $\mathrm{c}-\mathrm{Myc}$ (cell proliferative protein) than the tumour tissue from mice in the control group; however, no change in $\mathrm{c}-\mathrm{Myc}$ levels was observed in the mice treated with either drug alone (Figure 5C). Furthermore, immunohistochemical results confirmed that $\gamma-\mathrm{T} 3$ enhanced capecitabine inhibition of cyclin D1 (Figure 6).

$\gamma$-T3 inhibits the expression of metastatic proteins in CRC tissue. We also examined the expression of proteins involved in invasion and metastasis in CRC tissue samples (Figure 5D). Our results showed that tumour tissue from mice treated with $\gamma$-T3 alone or capecitabine alone had moderately lower expression of ICAM-1, CXCR4, MMP-9, and VEGF than tumour tissue from the mice in the control group. The tumour tissue from mice treated with both $\gamma$-T3 and capecitabine had even lower levels of these proteins than the tumour tissue from mice treated with either drug alone (Figure 5D). The immunohistochemical analysis results further confirmed the western blot results. The expression of invasion and metastatic proteins MMP-9, CXCR4, and VEGF was downregulated by $\gamma$-T3 alone and capecitabine alone. The tumour tissue from mice treated with both $\gamma$-T3 and capecitabine had lower levels of these proteins than the tumour tissue from mice treated with either drug alone (Figure 6).

$\gamma$-T3 downregulates inflammatory transcription factor NF- $\kappa \mathrm{B} /$ p65 in CRC tissue. Because cell survival proteins (Bcl-2, Bcl-xL, cIAP-1, cIAP-2, and survivin), proliferation proteins (cyclin D1 and $\mathrm{c}-\mathrm{Myc}$ ), and invasion and metastatic proteins (MMP-9, ICAM-1, CXCR4, and VEGF) are all regulated by $\mathrm{NF}-\kappa \mathrm{B} / \mathrm{p} 65$, we investigated whether $\gamma$-T3 suppressed the expression of NF- $\kappa \mathrm{B}$ activation. Immunohistochemical analysis results showed that tumour tissue from mice treated with $\gamma$-T3 alone or capecitabine alone had lower levels of NF- $\kappa \mathrm{B}$ than tumour tissue from mice in the control group (Figure 6). The combination treatment of $\gamma$-T3 and capecitabine was more effective than treatment with either drug alone. 
A

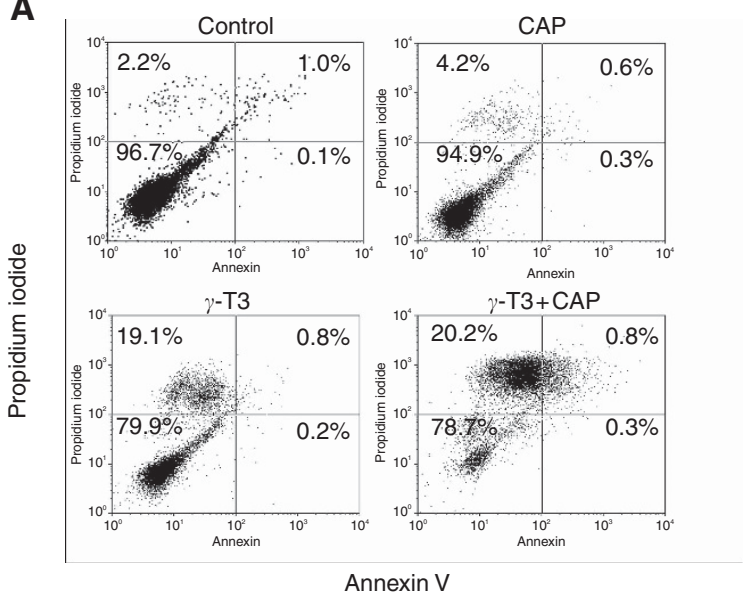

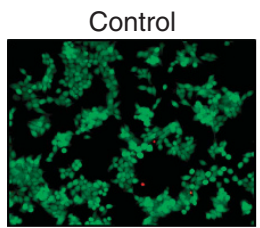

$0.9 \pm 0.7 \%$

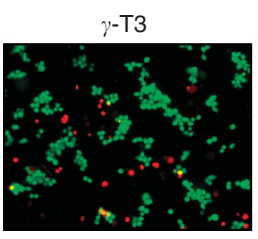

$26.4 \pm 1.9 \%$

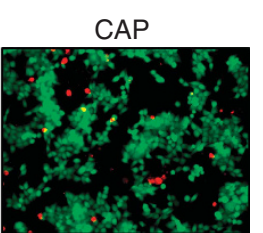

$11.4 \pm 0.3 \%$

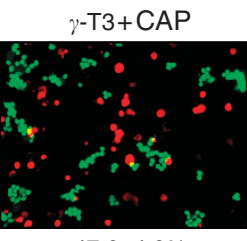

$47.6 \pm 4.0 \%$

B

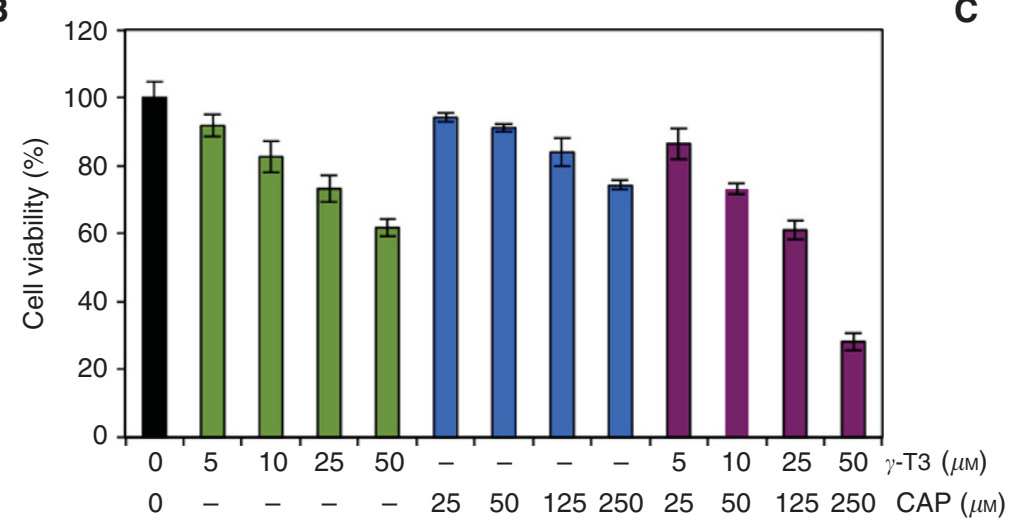

C
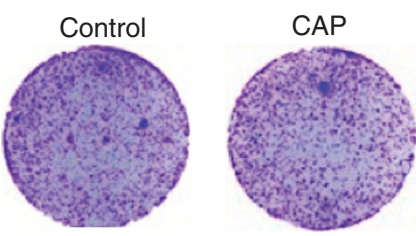

$\gamma-\mathrm{T} 3$

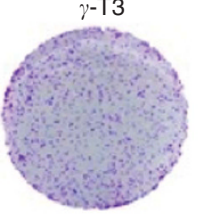

$\gamma-\mathrm{T} 3+\mathrm{CAP}$
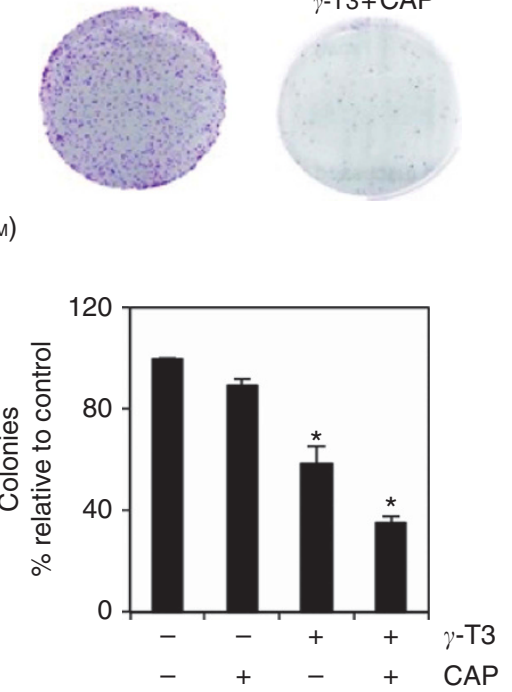

$\begin{array}{llll}1 & 0.9 & 0.5 & 0.5 \text { Fold }\end{array}$

\ $N-K B$

E

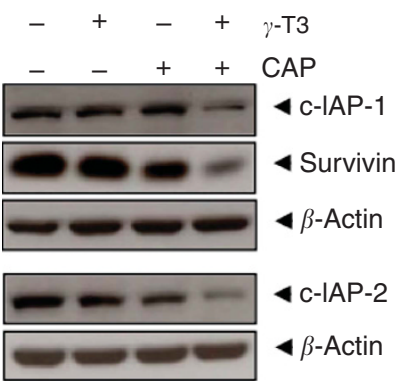

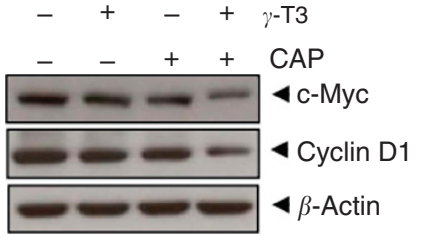

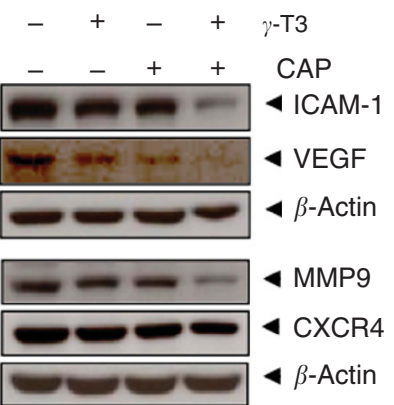

Figure 2. $\gamma$-Tocotrienol $(\gamma$-T3) enhances capecitabine (CAP) inhibition of cell growth in CRC cells. (A) The HCT 116 cells were treated with $\gamma$-T3 $(25 \mu \mathrm{M})$ for $6 \mathrm{~h}$ and then with CAP $(20 \mu \mathrm{M})$ for $18 \mathrm{~h}$. Cell death was determined by Annexin V/PI fluorescence-activated cell sorting analysis (left panel) and live/dead cell assay (right panel). (B) The HCT 116 cells were seeded in quadruplicate and treated with indicated concentration of $\gamma$-T3 alone and CAP alone or in combination for $24 \mathrm{~h}$. Cell viability was then analysed by the MTT method. (C) The HCT 116 cells were treated with $\gamma$-T3 for $6 \mathrm{~h}$ and then were treated with CAP for $18 \mathrm{~h}$. The medium was replaced, and after 9 days the cells were stained with crystal violet and were counted for colony formation (lower panel). *Significant $(P<0.05)$ over controls. (D) The HCT 116 cells were incubated with $\gamma$-T3 $(25 \mu \mathrm{M})$ for $6 \mathrm{~h}$ and then were treated with CAP $(20 \mu \mathrm{M})$ for $18 \mathrm{~h}$. Nuclear extracts were analysed for NF- $\kappa$ B activation by electrophoretic mobility shift assay. (E) HCT 116 cells were treated with $\gamma$-T3 $(25 \mu \mathrm{M})$ for $6 \mathrm{~h}$ and then with CAP $(20 \mu \mathrm{M})$ for $18 \mathrm{~h}$. The whole-cell extract was analysed for cell survival, proliferation, invasion, and metastatic proteins in CRC cells by western blotting. 
A

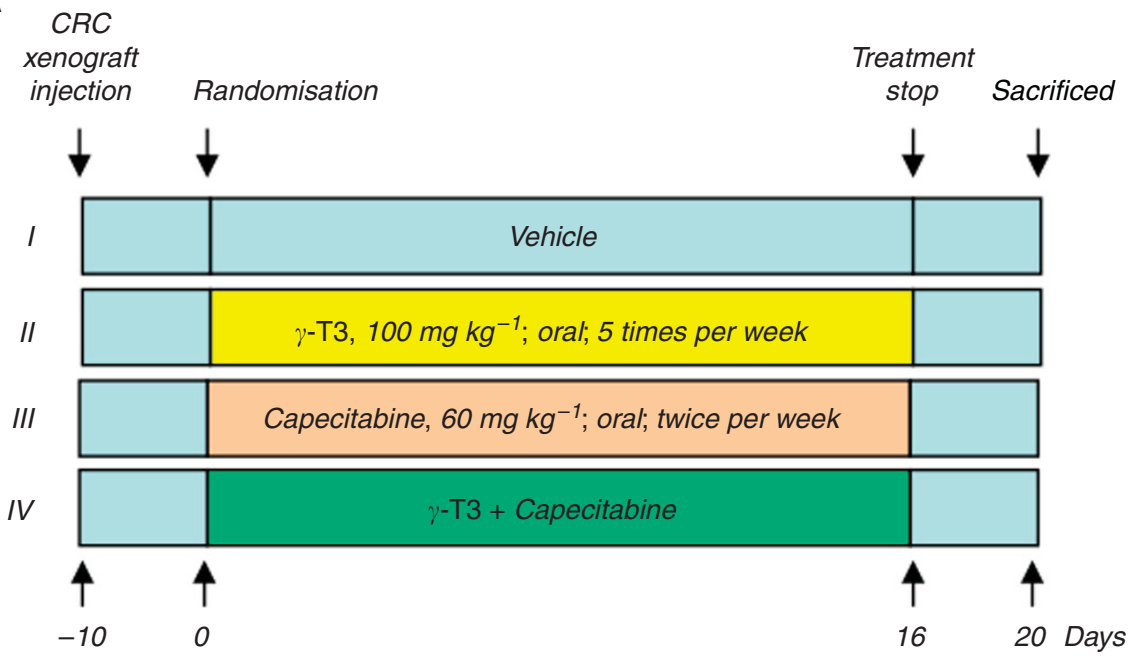

B
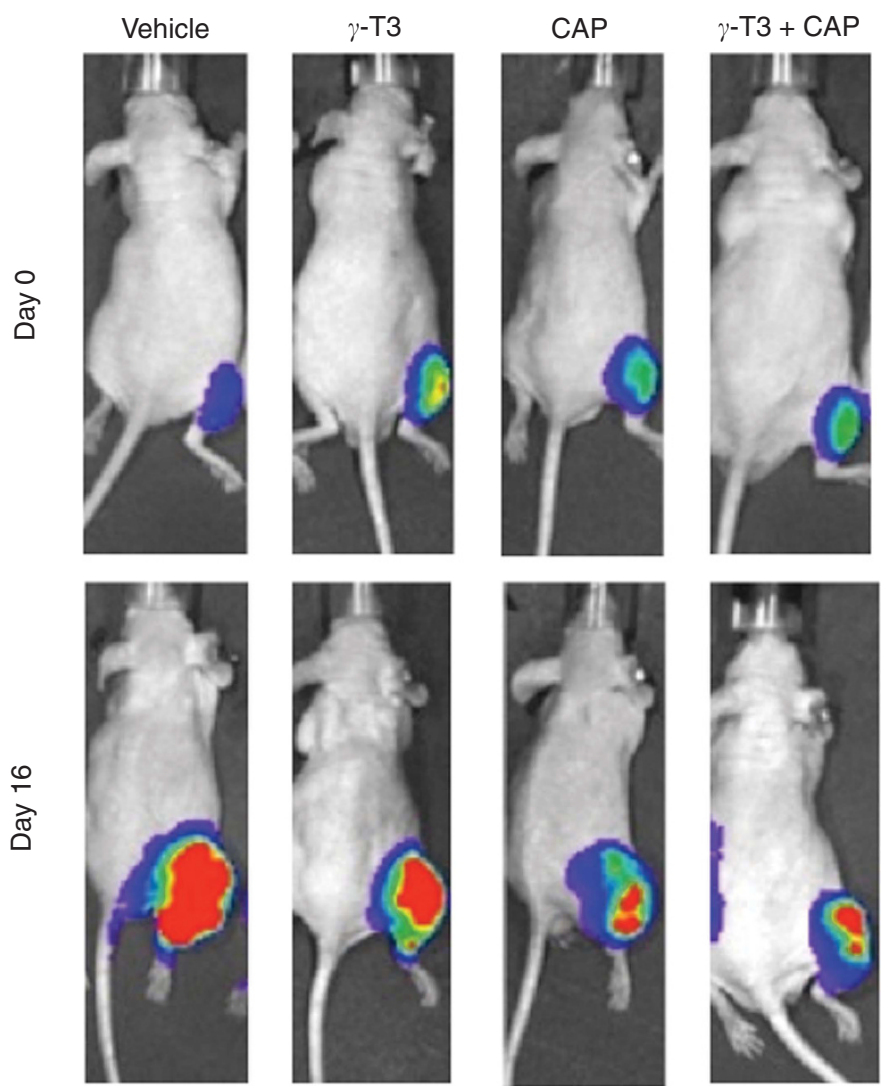

Figure 3. $\gamma$-Tocotrienol $(\gamma$-T3) enhances the ability of capecitabine to inhibit the growth of CRC xenograft tumours in nude mice. (A) Schematic representation for the treatment of mice $(n=5)$ with $\gamma$-T3 alone, capecitabine alone, and combinations of the two agents. (B) The $\gamma$-T3 and capecitabine (CAP) in combination suppressed the growth of CRC tumours in the xenograft mouse model. On day 0 and day 16 after CRC tumour implantation, bioluminescence imaging was performed on live, anaesthetised mice.

\section{DISCUSSION}

CRC incidence rates have declined $\sim 2 \%-3 \%$ per year over the past few years in the United States, which could be attributed to the early detection and removal of colonic polyps. However, more effective treatments with minimal side effects and low cost are needed. The US Food and Drug Administration has approved several drugs for CRC, including bevacizumab (targeting VEGF), cetuximab (targeting EGFR), regorafenib (kinase inhibitor), and capecitabine. These drugs are very expensive and can have serious side effects, and patients can also develop resistance (Vlacich and Coffey, 2011; Yeung and Tebbutt, 2012; Aprile et al, 2013). Thus, new strategies are needed to replace or complement current therapies. We showed that $\gamma$-T3, which is a very safe natural compound, exerted anticancer activity against CRC and enhanced the effects of capecitabine in inhibiting tumour growth via regulation of cell survival proteins both in vitro and in vivo.

We found that $\gamma$-T3 inhibited the proliferation of CRC cells with mutated KRAS (HCT 116) and those with wild-type KRAS (HT-29 and Caco-2). Another study showed that $\gamma$-T3 suppressed Ras and RhoA prenylation that suppressed growth in human lung 
A

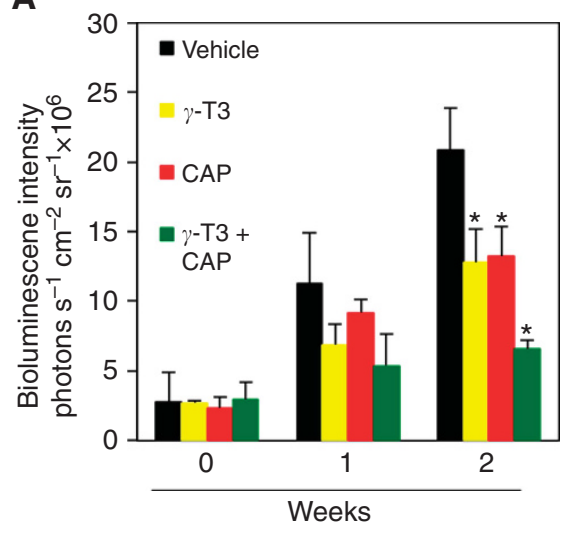

B

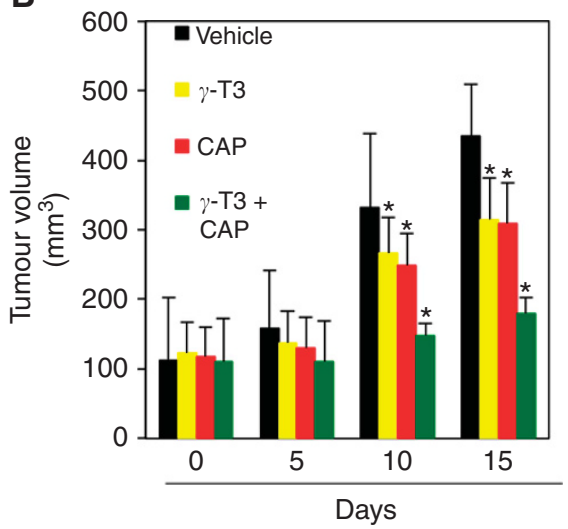

C

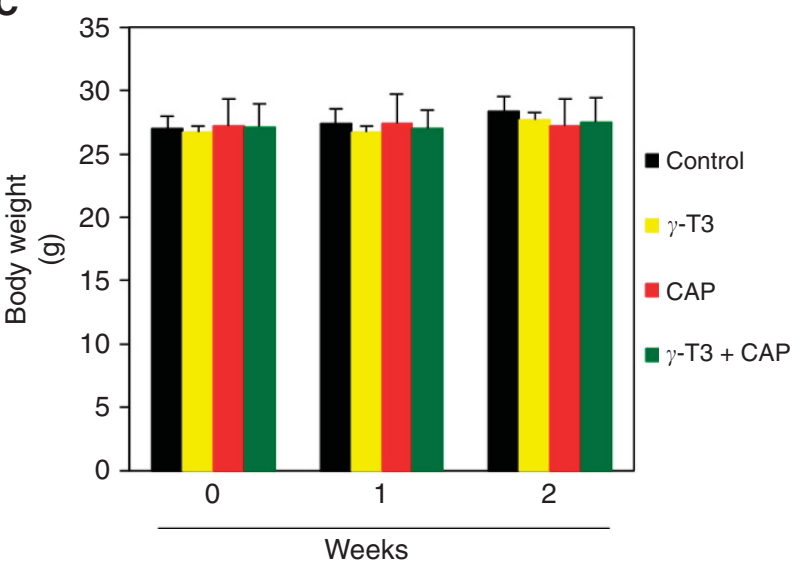

Figure 4. $\gamma$-Tocotrienol $(\gamma$-T3) and capecitabine (CAP) in combination suppresses CRC tumour growth in nude mice. (A) Tumour volume in the implanted mice was measured at the indicated time points with live bioluminescence imaging. *Significant $(P<0.05)$ over control. (B) Tumour volume in the implanted mice was measured after 5, 10, and 15 days of treatment. Tumour volume was measured using Vernier calipers and the formula $0.5 \times L \times W^{2}$, where $L$ and $W$ represent the length and width of tumours, respectively. ${ }^{*}$ Significant $(P<0.05)$ over vehicle control. (C) The $\gamma$-T3 and capecitabine did not affect the body weight of the mice. The body weight of mice was measured before and after 1 and 2 weeks of treatment.

adenocarcinoma cells with mutated RAS (A549 cells) (Yano et al, 2005). The inhibition of cell growth and proliferation by $\gamma$-T3 appeared to be due to the suppression of several biomarkers. We found that $\gamma$-T3 alone and in combination with capecitabine inhibited proliferative proteins cyclin D1 and Ki-67, indicating one of the probable mechanisms of the antitumourigenic potential of $\gamma$-T3. Our results support those of Gysin et al (2002) who showed that $\gamma$-tocopherol inhibited cell proliferation by reducing cyclin D1 and cyclin E levels.

Our results show that $\gamma$-T3 enhanced the anticancer effects of capecitabine against CRC cell lines. These results support those of a previous study that showed that the combination of atorvastatin and $\gamma$-T3 synergistically inhibited CRC growth in HCT 116 and HT-29 cells (Yang et al, 2010). Previously, we reported that $\gamma$-T3 at low concentrations can sensitise colon cancer cells to TRAIL by modulating apoptotic pathways (Kannappan et al, 2010). In the current study, we found that $\gamma$-T3 in combination with capecitabine downregulated the expression of cell survival proteins (survivin, $\mathrm{Bcl}-\mathrm{xL}$, and $\mathrm{Bcl}-2$ ) and invasion and metastatic proteins (VEGF, MMP-9, ICAM-1, and CXCR4), further supporting the therapeutic potential of $\gamma$-T3 for CRC.

We found that $\gamma$-T3 alone significantly inhibited CRC growth in a xenograft mouse model, and this effect was comparable to that of capecitabine alone. When the two agents were used in combination, they were much more effective. Previously, we showed that $\gamma$-T3 enhanced the antitumour effect of gemcitabine against pancreatic cancer in a xenograft nude mouse model (Kunnumakkara et al, 2010), but whether $\gamma$-T3 has the same effects in other cancers is unknown. Another study showed that $\gamma$-T3 alone suppressed tumour growth in a murine xenograft model of human gastric cancer, and this effect was enhanced by capecitabine (Manu et al, 2012). In the current study, we also observed that $\gamma$-T3 was very well tolerated by the animals.

We also found that $\gamma-\mathrm{T} 3$ alone inhibited activation of NF- $\kappa \mathrm{B}$ in CRC (in vitro and in vivo). This transcription factor NF- $\kappa \mathrm{B}$ is reported to be constitutively activated in CRC (Prasad et al, 2010) and regulate the growth of tumour cells. Our results showed that, in CRC, $\gamma$-T3 inhibited several antiapoptotic proteins regulated by $\mathrm{NF}-\kappa \mathrm{B}$, including survivin, $\mathrm{Bcl}-2, \mathrm{Bcl}-\mathrm{xL}$ and cIAPs, suggesting that $\gamma$-T3 enhanced the apoptotic effect of capecitabine in CRC by inhibiting antiapoptotic proteins.

In the current study, we found that $\gamma$-T3 suppressed the expression of invasion and metastasis biomarkers CXCR4 and MMP-9 and angiogenic biomarker VEGF in CRC tissue. Previous studies have reported the role of CXCR4 overexpression in CRC metastasis (Tachibana et al, 1998; Zeelenberg et al, 2003). Increased expression of CXCR4 has also been associated with an increased risk of recurrence and poor survival in patients with CRC (Kim et al, 2005). Another study showed that enhanced VEGF production led to angiogenesis, metastasis, and proliferation of human CRC (Takahashi and Loo, 2004). The overexpression of CXCR4 and VEGF was predictive of early distant relapse in 


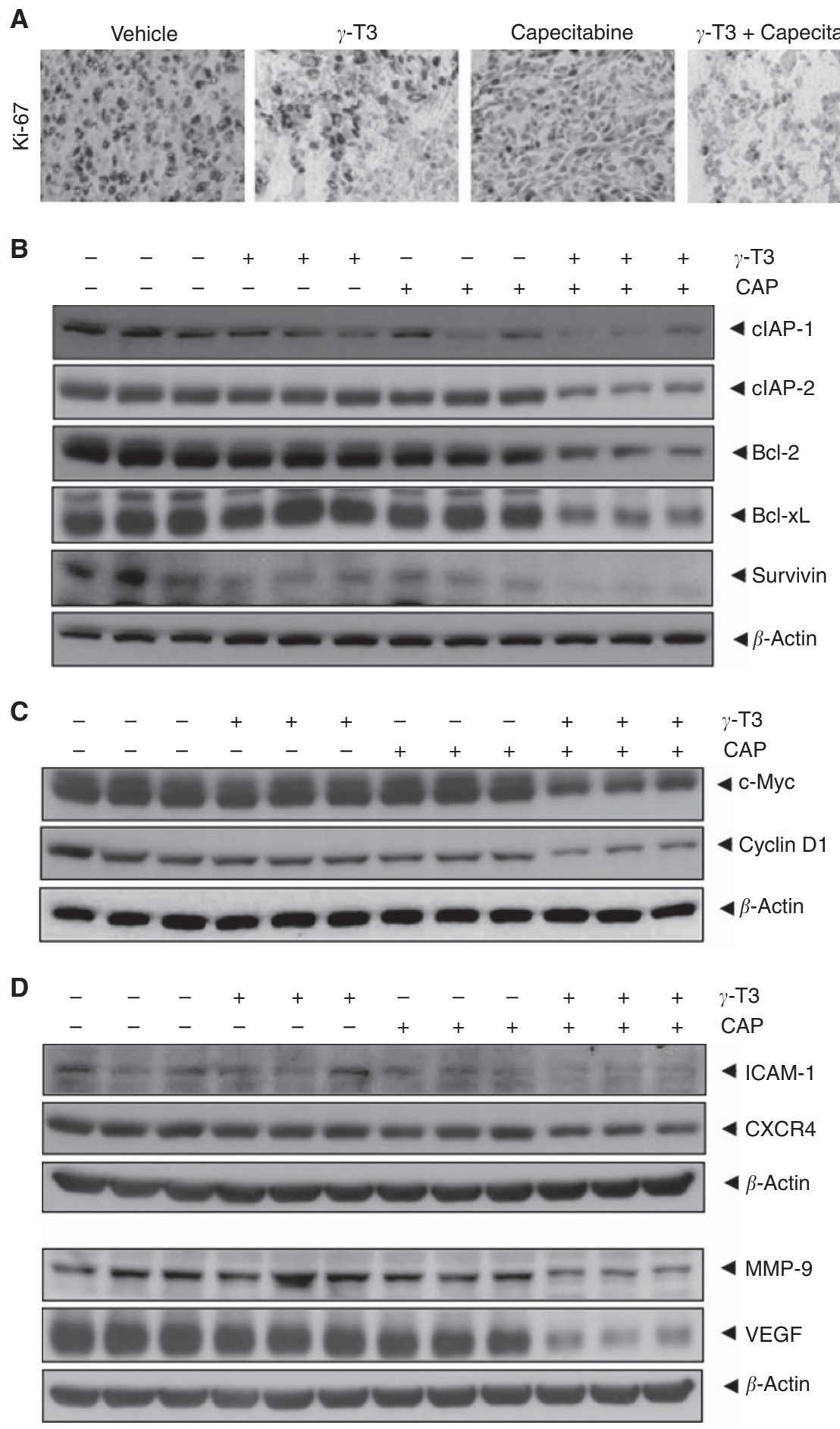

Figure 5. $\gamma$-Tocotrienol $(\gamma-\mathrm{T} 3)$ and capecitabine (CAP) in combination inhibit the expression of several proteins related to proliferation, survival, and metastasis. Combination treatment inhibited (A) proliferation marker (Ki-67) as determined by immunohistochemical analysis, (B) cell survival proteins, $(C)$ proliferation proteins, and (D) metastatic proteins in xenograft tumours from mice as analysed by western blotting.

patients with stage II and III CRC (Ottaiano et al, 2006). We also found that $\gamma$-T3 suppressed the expression of ICAM-1, an NF- $\kappa$ Bregulated gene related to invasion, in CRC.

This anticancer activity of $\gamma-\mathrm{T} 3$ is very likely closely associated with its well-defined pharmacokinetic properties. For example, when tocotrienol-rich fraction (TRF) was given orally to the mice, the maximum concentrations of $\gamma$-T3 was reported in the plasma after $6 \mathrm{~h}$ of treatment (Miyoshi et al, 2011). When administered intravenously in rats at $2 \mathrm{mg} \mathrm{kg}^{-1}$, the concentration of $\gamma$-T3 reached to a maximum $\left(\mathrm{C}_{\max }\right)$ of $17515 \pm 6526 \mathrm{ng} \mathrm{ml}^{-1}$ and then declined rapidly (Liang et al, 2013). To increase the bioavailability, TRF was complexed with cyclodextrin and administered orally to the mice. The plasma $\gamma$-T3 concentration was increased to 1.4 -fold in the mice when administered with TRF/cyclodextin as compared with TRF alone (Miyoshi et al, 2011). The half-life for $\gamma$ - and $\alpha$-tocotrienols has been reported in the range of $3.8-4.4 \mathrm{~h}$, respectively (Yap et al, 2001; Schwedhelm et al, 2003). However, elimination of half-lives of tocotrienols was shown to be shorter, 

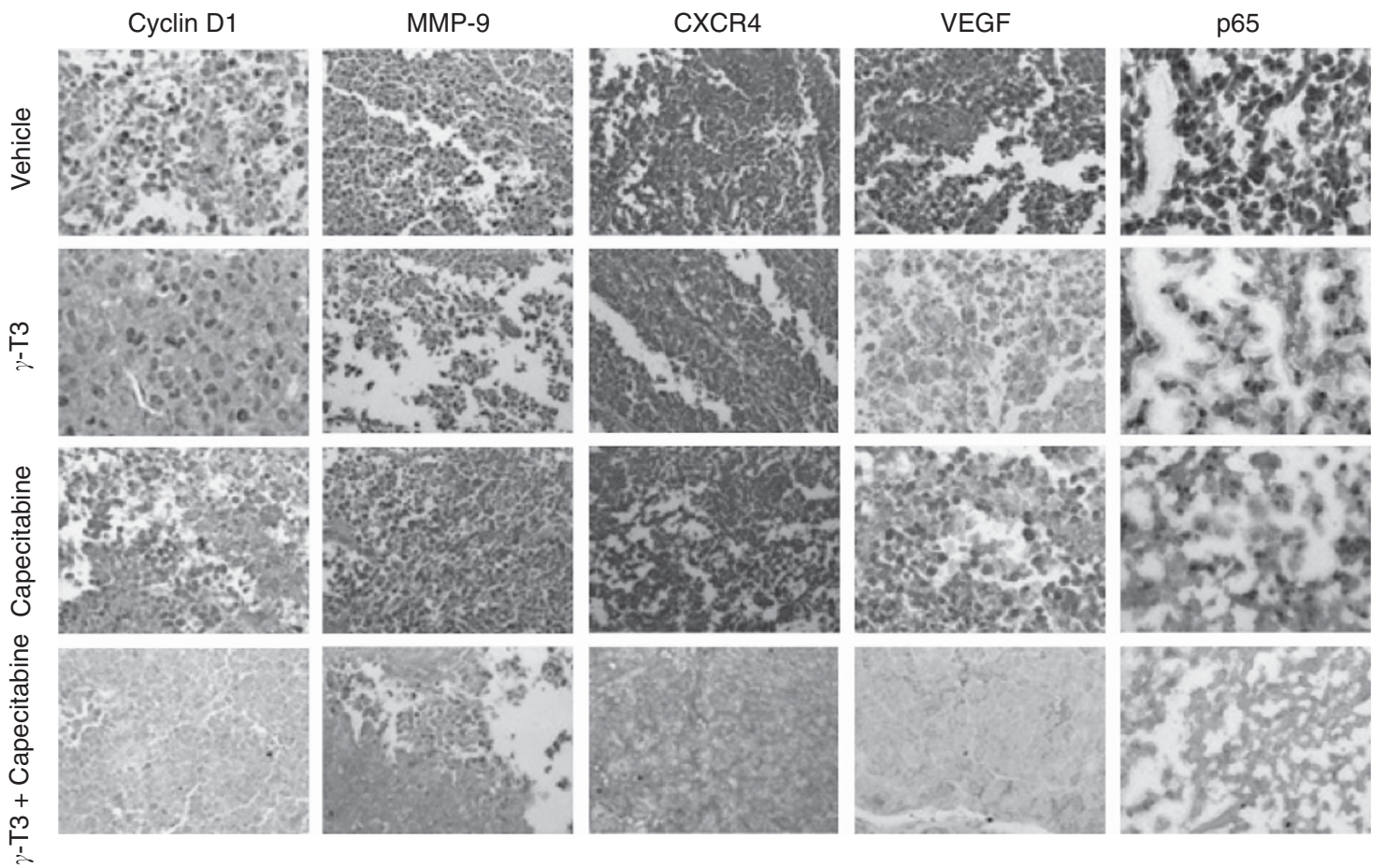

Figure 6. $\gamma$-Tocotrienol $(\gamma-$ T3) and capecitabine in combination inhibit NF- $\kappa$ B and expression of its regulated gene products cyclin D1, MMP-9, CXCR4, and VEGF in xenograft tumours from mice. Tissue sections from the tumours were subjected to immunohistochemical analysis. Pictures were captured with a Photometrics Scientific CoolSNAP CF colour camera (Photometrics) and analysed with MetaMorph software, version 4.6.5 (Molecular Devices).

that is, $4.3,4.4$, and $2.3 \mathrm{~h}$ for $\alpha-, \gamma$-, and $\delta$-T3, respectively (Yap et al, 2001; Schwedhelm et al, 2003). These pharmacokinetic studies indicate the therapeutic values of $\gamma$-T3 against cancer.

Our results suggest that $\gamma$-T3 has substantial potential for treating patients with $\mathrm{CRC}$ and can potentiate the antitumour and antimetastatic effects of capecitabine by inhibiting NF- $\kappa \mathrm{B}$ and associated biomarkers that are involved in proliferation, angiogenesis, invasion, and metastasis. Our in vitro and in vivo findings warrant further studies to explore the potential of $\gamma-\mathrm{T} 3$ as an anticancer agent in patients with CRC.

\section{ACKNOWLEDGEMENTS}

We thank Dr Jill Delsigne in the Department of Scientific Publications at The University of Texas MD Anderson Cancer Center for carefully editing the manuscript. This work was supported by a grant from the Malaysian Palm Oil Board.

\section{CONFLICT OF INTEREST}

The authors declare no conflict of interest.

\section{REFERENCES}

Aggarwal B, Prasad S, Sung B, Krishnan S, Guha S (2013) Prevention and treatment of colorectal cancer by natural agents from mother nature. Curr Colorectal Cancer Rep 9(1): 37-56.

Aggarwal BB, Sundaram C, Prasad S, Kannappan R (2010) Tocotrienols, the vitamin $\mathrm{E}$ of the 21st century: its potential against cancer and other chronic diseases. Biochem Pharmacol 80(11): 1613-1631.

Ahn KS, Sethi G, Krishnan K, Aggarwal BB (2007) Gamma-tocotrienol inhibits nuclear factor-kappaB signaling pathway through inhibition of receptor-interacting protein and TAK1 leading to suppression of antiapoptotic gene products and potentiation of apoptosis. J Biol Chem 282(1): 809-820.

Aprile G, Macerelli M, Giuliani F (2013) Regorafenib for gastrointestinal malignancies: from preclinical data to clinical results of a novel multitarget inhibitor. BioDrugs 27(3): 213-224.

Campbell SE, Rudder B, Phillips RB, Whaley SG, Stimmel JB, Leesnitzer LM, Lightner J, Dessus-Babus S, Duffourc M, Stone WL, Menter DG, Newman RA, Yang P, Aggarwal BB, Krishnan K (2011) gamma-Tocotrienol induces growth arrest through a novel pathway with TGFbeta2 in prostate cancer. Free Radic Biol Med 50(10): 1344-1354.

Chaturvedi MM, Mukhopadhyay A, Aggarwal BB (2000) Assay for redoxsensitive transcription factor. Methods Enzymol 319: 585-602.

Chin SF, Hamid NA, Latiff AA, Zakaria Z, Mazlan M, Yusof YA, Karim AA, Ibahim J, Hamid Z, Ngah WZ (2008) Reduction of DNA damage in older healthy adults by Tri E Tocotrienol supplementation. Nutrition 24(1): 1-10.

Chou TC (2006) Theoretical basis, experimental design, and computerized simulation of synergism and antagonism in drug combination studies. Pharmacol Rev 58(3): 621-681.

Gould MN, Haag JD, Kennan WS, Tanner MA, Elson CE (1991) A comparison of tocopherol and tocotrienol for the chemoprevention of chemically induced rat mammary tumors. Am J Clin Nutr 53(4 Suppl): 1068S-1070S.

Gysin R, Azzi A, Visarius T (2002) Gamma-tocopherol inhibits human cancer cell cycle progression and cell proliferation by down-regulation of cyclins. FASEB J 16(14): 1952-1954.

Hiura Y, Tachibana H, Arakawa R, Aoyama N, Okabe M, Sakai M, Yamada K (2009) Specific accumulation of gamma- and deltatocotrienols in tumor and their antitumor effect in vivo. J Nutr Biochem 20(8): 607-613.

Hsieh TC, Elangovan S, Wu JM (2010) Differential suppression of proliferation in MCF-7 and MDA-MB-231 breast cancer cells exposed to alpha-, gamma- and delta-tocotrienols is accompanied by altered expression of oxidative stress modulatory enzymes. Anticancer Res 30(10): 4169-4176.

Kannappan R, Gupta SC, Kim JH, Aggarwal BB (2012) Tocotrienols fight cancer by targeting multiple cell signaling pathways. Genes Nutr 7(1): 43-52.

Kannappan R, Ravindran J, Prasad S, Sung B, Yadav VR, Reuter S, Chaturvedi MM, Aggarwal BB (2010) Gamma-tocotrienol promotes 
TRAIL-induced apoptosis through reactive oxygen species/extracellular signal-regulated kinase/p53-mediated upregulation of death receptors. Mol Cancer Ther 9(8): 2196-2207.

Kim J, Takeuchi H, Lam ST, Turner RR, Wang HJ, Kuo C, Foshag L, Bilchik AJ, Hoon DS (2005) Chemokine receptor CXCR4 expression in colorectal cancer patients increases the risk for recurrence and for poor survival. J Clin Oncol 23(12): 2744-2753.

Kuhad A, Bishnoi M, Tiwari V, Chopra K (2009) Suppression of NF-kappabeta signaling pathway by tocotrienol can prevent diabetes associated cognitive deficits. Pharmacol Biochem Behav 92(2): 251-259.

Kunnumakkara AB, Diagaradjane P, Anand P, Harikumar KB, Deorukhkar A, Gelovani J, Guha S, Krishnan S, Aggarwal BB (2009) Curcumin sensitizes human colorectal cancer to capecitabine by modulation of cyclin D1, COX-2, MMP-9, VEGF and CXCR4 expression in an orthotopic mouse model. Int J Cancer 125(9): 2187-2197.

Kunnumakkara AB, Sung B, Ravindran J, Diagaradjane P, Deorukhkar A, Dey S, Koca C, Yadav VR, Tong Z, Gelovani JG, Guha S, Krishnan S, Aggarwal BB (2010) \{Gamma\}-tocotrienol inhibits pancreatic tumors and sensitizes them to gemcitabine treatment by modulating the inflammatory microenvironment. Cancer Res 70(21): 8695-8705.

Lee BY, Sonnenberg A (2013) Time trends of mortality from colorectal cancer in the United States: a birth-cohort analysis. JAMA Intern Med 173(12): $1148-1150$.

Liang S, Bian X, Ma J, Arogunjo M, Deorukhkar AA, Krishnan S, Xie H (2013) Development and validation of a sensitive LC/MS/MS method for the determination of gamma-tocotrienol in rat plasma: application to pharmacokinetic studies. Biomed Chromatogr 27(1): 58-66.

Liu Z, Guo Y, Li J, Xu J, Liu B (2013) Cotransfection of survivin and CD44v3 short hairpin RNAs affects proliferation, apoptosis, and invasiveness of colorectal cancer. Dig Dis Sci 58(6): 1590-1601.

Manu KA, Shanmugam MK, Ramachandran L, Li F, Fong CW, Kumar AP, Tan P, Sethi G (2012) First evidence that gamma-tocotrienol inhibits the growth of human gastric cancer and chemosensitizes it to capecitabine in a xenograft mouse model through the modulation of NF-kappaB pathway. Clin Cancer Res 18(8): 2220-2229.

Miyoshi N, Wakao Y, Tomono S, Tatemichi M, Yano T, Ohshima H (2011) The enhancement of the oral bioavailability of gamma-tocotrienol in mice by gamma-cyclodextrin inclusion. J Nutr Biochem 22(12): 1121-1126.

Nakagawa K, Shibata A, Yamashita S, Tsuzuki T, Kariya J, Oikawa S, Miyazawa T (2007) In vivo angiogenesis is suppressed by unsaturated vitamin E, tocotrienol. J Nutr 137(8): 1938-1943.

Ottaiano A, Franco R, Aiello Talamanca A, Liguori G, Tatangelo F, Delrio P, Nasti G, Barletta E, Facchini G, Daniele B, Di Blasi A, Napolitano M, Ierano C, Calemma R, Leonardi E, Albino V, De Angelis V, Falanga M, Boccia V, Capuozzo M, Parisi V, Botti G, Castello G, Vincenzo Iaffaioli R, Scala S (2006) Overexpression of both CXC chemokine receptor 4 and vascular endothelial growth factor proteins predicts early distant relapse in stage II-III colorectal cancer patients. Clin Cancer Res 12(9): 2795-2803.

Prasad S, Ravindran J, Aggarwal BB (2010) NF-kappaB and cancer: how intimate is this relationship. Mol Cell Biochem 336(1-2): 25-37.

Qureshi AA, Qureshi N, Wright JJ, Shen Z, Kramer G, Gapor A, Chong YH, DeWitt G, Ong A, Peterson DM, Bradlow BA (1991) Lowering of serum cholesterol in hypercholesterolemic humans by tocotrienols (palmvitee). Am J Clin Nutr 53(4 Suppl): 1021S-1026S.

Samant GV, Sylvester PW (2006) gamma-Tocotrienol inhibits ErbB3dependent PI3K/Akt mitogenic signalling in neoplastic mammary epithelial cells. Cell Prolif 39(6): 563-574.
Schaffer S, Muller WE, Eckert GP (2005) Tocotrienols: constitutional effects in aging and disease. J Nutr 135(2): 151-154.

Schwedhelm E, Maas R, Troost R, Boger RH (2003) Clinical pharmacokinetics of antioxidants and their impact on systemic oxidative stress. Clin Pharmacokinet 42(5): 437-459.

Sen CK, Khanna S, Roy S (2004) Tocotrienol: the natural vitamin E to defend the nervous system? Ann NY Acad Sci 1031: 127-142.

Shah SJ, Sylvester PW (2005) Gamma-tocotrienol inhibits neoplastic mammary epithelial cell proliferation by decreasing Akt and nuclear factor kappaB activity. Exp Biol Med (Maywood) 230(4): 235-241.

Siegel RL, Miller KD, Jemal A (2015) Cancer statistics, 2015. CA Cancer J Clin 65(1): 5-29.

Sun W, Wang Q, Chen B, Liu J, Liu H, Xu W (2008) Gamma-tocotrienolinduced apoptosis in human gastric cancer SGC-7901 cells is associated with a suppression in mitogen-activated protein kinase signalling. $\mathrm{Br} \mathrm{J}$ Nutr 99(6): 1247-1254

Tachibana K, Hirota S, Iizasa H, Yoshida H, Kawabata K, Kataoka Y, Kitamura Y, Matsushima K, Yoshida N, Nishikawa S, Kishimoto T, Nagasawa T (1998) The chemokine receptor CXCR4 is essential for vascularization of the gastrointestinal tract. Nature 393(6685): 591-594.

Takahashi K, Loo G (2004) Disruption of mitochondria during tocotrienolinduced apoptosis in MDA-MB-231 human breast cancer cells. Biochem Pharmacol 67(2): 315-324.

Torre LA, Bray F, Siegel RL, Ferlay J, Lortet-Tieulent J, Jemal A (2015) Global cancer statistics, 2012. CA Cancer J Clin 65(2): 87-108.

Vlacich G, Coffey RJ (2011) Resistance to EGFR-targeted therapy: a family affair. Cancer Cell 20(4): 423-425.

Wada S, Satomi Y, Murakoshi M, Noguchi N, Yoshikawa T, Nishino H (2005) Tumor suppressive effects of tocotrienol in vivo and in vitro. Cancer Lett 229(2): 181-191.

Yamada Y, Obayashi M, Ishikawa T, Kiso Y, Ono Y, Yamashita K (2008) Dietary tocotrienol reduces UVB-induced skin damage and sesamin enhances tocotrienol effects in hairless mice. J Nutr Sci Vitaminol (Tokyo) 54(2): 117-123.

Yang Z, Xiao H, Jin H, Koo PT, Tsang DJ, Yang CS (2010) Synergistic actions of atorvastatin with gamma-tocotrienol and celecoxib against human colon cancer HT29 and HCT116 cells. Int J Cancer 126(4): 852-863.

Yano Y, Satoh H, Fukumoto K, Kumadaki I, Ichikawa T, Yamada K, Hagiwara K, Yano T (2005) Induction of cytotoxicity in human lung adenocarcinoma cells by 6-O-carboxypropyl-alpha-tocotrienol, a redoxsilent derivative of alpha-tocotrienol. Int J Cancer 115(5): 839-846.

Yap SP, Yuen KH, Wong JW (2001) Pharmacokinetics and bioavailability of alpha-, gamma- and delta-tocotrienols under different food status. J Pharm Pharmacol 53(1): 67-71.

Yeung Y, Tebbutt NC (2012) Bevacizumab in colorectal cancer: current and future directions. Expert Rev Anticancer Ther 12(10): 1263-1273.

Zeelenberg IS, Ruuls-Van Stalle L, Roos E (2003) The chemokine receptor CXCR4 is required for outgrowth of colon carcinoma micrometastases. Cancer Res 63(13): 3833-3839.

This work is published under the standard license to publish agreement. After 12 months the work will become freely available and the license terms will switch to a Creative Commons AttributionNonCommercial-Share Alike 4.0 Unported License. 